\title{
Stabilitation Research of the Tunnel Anchorage of Dadu River Bridge in Luding in Yaan to Kangding Expressway
}

\author{
Wen Lina $^{1,2}$, Cheng Qiangong ${ }^{1}$, Cheng Qiang ${ }^{2}$, Guo Xifeng ${ }^{3}$ \\ ${ }^{1}$ Faculty of Geosciences and Environmental Engineering, Southwest Jiaotong University, Chengdu, China \\ ${ }^{2}$ Highway Planning Survey, Design and Research Institute, Sichuan Provincial Transport Department, Chengdu, China \\ ${ }^{3}$ Yangtze River Academy of Sciences, Yangtze River Water Resources Commission, Wuhan, China
}

Email address:

26879619@qq.com (Wen Lina), $1094434773 @ q q . c o m$ (Cheng Qiangong)

\section{To cite this article:}

Wen Lina, Cheng Qiangong, Cheng Qiang, Guo Xifeng. Stabilitation Research of the Tunnel Anchorage of Dadu River Bridge in Luding in Yaan to Kangding Expressway. American Journal of Civil Engineering. Vol. 5, No. 4, 2017, pp. 196-204. doi: 10.11648/j.ajce.20170504.11

Received: May 12, 2017; Accepted: June 9, 2017; Published: June 14, 2017

\begin{abstract}
Based on features of indoor rock mechanics test, the in situ test and rock mass classification result, through established numerical analysis model of the tunnel anchor model drawing test, using the model observed values of surrounding rock deformation, using intelligent inversion method to inverting the displacement creep and mechanical parameters and provides more accurate and reasonable rock mass mechanics parameters to analyze the stability of surrounding rock tunnel anchorage of Dadu River bridge from Yaan to Kangding expressway in Lu Ding. This paper uses LSSVM and PSO analysis model and FLAC ${ }^{3 \mathrm{D}}$ numerical methods to realize the intelligent displacement inversion. Through the anchor parameters inversion of the model, and establish the solid bridge anchor numerical model, analysis of anchor tunnel excavation, load and overload condition of deformation and internal force, and then analyze the stability of tunnel anchor. Under the design load, anchorage roof and side wall stress relaxation zone in the plastic zone, floor rock mass basic in flexible working condition. Increase the force of main cable and 7P, shear failure and anchor rock contact area, increase the displacement of anchorage is nonlinear. Under the overload condition, the anchor rock rupture increased significantly and produce compression, the plastic zone to the development of deep surrounding rock anchorage above, failure mode for compressive shear failure. The conclusion to provide technical support for tunnel anchor design, at the same time, provide reference for similar projects.
\end{abstract}

Keywords: Tunnel Anchor, Stability, Inversion

\section{Introduction}

Yaan to Kangding expressway is located in the transition from the western Sichuan basin to Qinghai-Tibet plateau, it is one of the four Tibetan expressway planning in Sichuan province. The altitude is from less than 600 meters to more than 3600 meters. Due to the extremely climate, the mountain route is very long. The under construction Ya Kang highway passes through the gorges region with extremely complex geomorphology and geology in the high intensity area for earthquake. The way has the characteristics of "very complicated terrain, extremely complex geological conditions, extremely complex climate and extremely vulnerable ecological conditions and extremely complex difficult conditions of construction" and the characteristics of "mountain, plateau and high speed".
Luding Dadu River bridge located in Tianba village of Luding County, the bridge cross the Dadu River in Luding hydroelectric power station in Zanli village. It is a main span of 1100 meters single span suspension bridge, the steel composite bridge system, main girder for steel truss beam, 27.0 meters wide and 8.2 meters high. The foundation of Yaan shore is tunnel anchorage and Kangding shore is gravity anchorage(JTG/T D65-05-2015).

Through the engineering geological investigation and validation of Luding tunnel excavation, alliterated adamellite is broken, class for $\mathrm{IV}_{3}$, secondary faults developed in rock mass and affect the deformation and stability of anchorage. The bridge was carried out by geological survey, indoor and field mechanics test, 1:10 scale tunnel anchorage model test etc, based on preliminary researches, this paper using the inversion method analyzing of the stability of tunnel anchor for rock mass parameters. 
Based on the rockmass parameters from tests, the three-dimensional elastoplastic analysis has been performed to simulate the complete sequence of construction including highway tunnel excavation, tunnel-type anchorage excavation, concrete in-situ casting, prestressed concrete anchorage, main cable installation, etc. for Siduhe suspension bridge. The failure pattern is that two anchorage bodies are pulled out which decline outsides ( $\mathrm{Zhu}, 2005$ ). According to bearing capacity problem of a tunnel anchorage at Yichang side for Siduhe suspension bridge, to study systematically the deformation and failure mechanism, the rheological characteristics and overloading capacities of the tunnel anchorage and its surrounding rock mass by a comprehensive rock mechanics research method are proposed. The total deformation of the actual tunnel anchorage is in the grade of $\mathrm{mm}$ with the designing load which will be supplied by the suspension bridge and untimate tensile bearing capacity is greater than 7.6 times of the design load (Wu, 2010). The numerical analysis and grey model to predict the anchorage stability for Chongqing Egongyan bridge, gray predict the ultimate bearing capacity of wall rock is 6.09 6.15 times of its design load(Xiao, 2005; Wu, 2003). Analyze the anchorage rock masses stability use the FLAC ${ }^{3 \mathrm{D}}$ numerical analysis. According to the overload test, the failure does not simply happen on the boundary of the anchorage and rock masses, but holding the surrounding rock appears as plug style tensile-shear complex failure $(\mathrm{Hu}, 2009)$. Under the action of excavation and design load, the rockmass stability of tunnel anchorage system of Aizhai Bridge was calculated by using $\mathrm{FLAC}^{3 \mathrm{D}}$. It was found that, for the anchoring, the tower-base and the highway tunnel are centrally located, so the influence with each other is distinct. Furthermore, the tunnel anchorage system isn't stable under the action of treble design load (Dong, 2005).

\section{Model Test of Inversion Analysis}

The anchorage of surrounding rock mainly undertake the tensile force. In order to better reflect the stability of wall rock tunnel anchor, based on the indoor mechanics test and in situ test and rock mass classification result, through established numerical analysis model of the tunnel anchor model drawing test, using the model observed values of surrounding rock deformation, adopted the intelligent inversion method to inverting the displacement creep parameters and mechanical parameters and provided more accurate and reasonable rock mass mechanics parameters to analyze the stability of surrounding rock tunnel anchorage. To obtain the inversion parameters and LSSVM model of rock mass displacement

In this paper, based on LSSVM established the nonlinear mapping relation between inversion parameters and the displacement of rock mass.

PSO produced the first group of random particles, and then find the optimal solution through iteration. In each iteration, the particles by tracking the two extreme value to update themselves. One is the optimal solution each particle to achieve in search of all, be individual extreme value $P_{\text {best }}$, the other is the optimal solution whole group of all particles achieved in search of all, known as the global extremum $g_{\text {best }}$. The $i$ the particle in groups, in $n$ dimension is expressed as $x_{i}=\left(x_{i 1}, x_{i 2} \ldots \ldots, x_{i n}\right)$, for its speed $v_{i}=\left(v_{i 1}, v_{i 2} \ldots \ldots, v_{i n}\right)$, individual extremum for the $i$ th a particle $P_{\text {best }}=\left(P_{i 1}, P_{i 2} \ldots \ldots, P_{i n}\right)$ and the particle swarm global extrema $g_{\text {best }}=\left(g_{1}, g_{2} \ldots \ldots, g_{n}\right)$. When find the two extreme value, use the type to update their speed and position:

$$
\begin{aligned}
& v_{i}(k+1)=w v_{i}(k)+c_{1} \operatorname{rand}_{1}\left(P_{\text {best }}-\right. \\
& \left.x_{i}(k)\right)+c_{2} \operatorname{rand}_{2}\left(g_{\text {best }}-x_{i}(k)\right) \\
& x_{i}(k+1)=x_{i}(k)+v_{i}(k+1)
\end{aligned}
$$

Among them, $c_{1}, c_{2}$ showed study factor, usually between the $(0,2)$. Then rand $_{1}$ and rand $_{2}$ as a random number between $(0,1), w$ as the momentum coefficient, its value can change along with the iteration algorithm.

Assume that $k$ group training sample data $\left\{x_{i}, y_{i}\right\}$, $(i=1,2, \ldots \ldots, k), x_{i} \in R^{n}$ as inversion parameters, $y_{i} \in R$ as displacement value of the gauge point. To establish the following relationship:

$$
\begin{gathered}
f: R^{n} \rightarrow R \\
y_{i}=f\left(x_{i}\right)(i=1,2, \ldots \ldots, k)
\end{gathered}
$$

The process of modeling is the process of looking for the above relations, according to the theory of least squares support vector machine (SVM), the corresponding inverse analysis model for:

$$
f(x)=\sum_{i=1}^{k} a_{i} K\left(x, x_{i}\right)+b
$$

$a$ and $b$ can be obtained through solution system of linear equations 1 to 5 .

Through analysis and comparison, this paper chooses radial basis kernel function inversion model is set up, and by using the particle swarm algorithm to search the optimal kernel function parameters $\sigma^{2}$ and the penalty factor $C$. the displacement back analysis of the objective function.

Intelligent displacement back analysis is established by the method of mapping relationship, the use of intelligent algorithm with inversion parameters on the global space search, looking for a set of parameters for inversion of the predicted values and the corresponding displacement value closest to the measured displacement. For practical engineering design and construction, often take a number of monitoring displacement value analysis. So you can put the error sum of squares of the minimum displacement of monitoring points predicted and the measured values as a basis for the choice for inversion parameters, the objective function desirable for: 


$$
F(X)=\sum_{i=1}^{n}\left[f_{i}(X)-y_{i}\right]^{2}
$$

$X=\left(x_{1}, x_{2}, \ldots \ldots, x_{k}\right)$ is a group of inversion of rock mass mechanics parameters, $f_{i}(X), y_{i}$ are respectively calculated values and measured values.

\section{Rock Elastic-Plastic Parameters Inversion of Model of Anchor}

\subsection{Calculation Condition}

According to the actual terrain model built with tunnel is excavated geological data, because of the anchorage of rock mass near mainly altered monzonitic granite, therefore only consider a kind of lithology, unilateral anchorage numerical calculation model is established, as shown in Figure 1, through $Y$ to the displacement constraint boundaries, simulation two anchor symmetry conditions. Calculating coordinates $x$ axis along the bridge axis direction (along the horizontal tensile direction of anchorage), $y$ axis vertical axis of the bridge, a positive $z$ axis vertical upward.

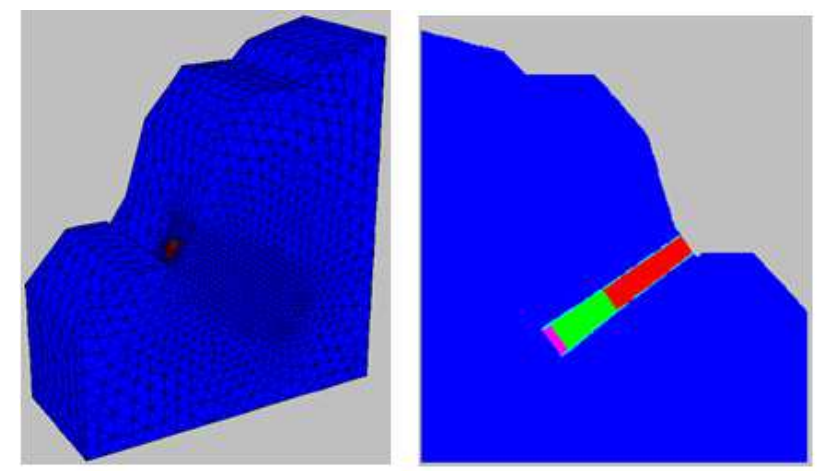

Figure 1. Model for calculating of model anchorage.

Surrounding the Mohr - Coulomb elastoplastic model, the anchorage body linear elastic constitutive model of concrete material used. Parameter inversion analysis mainly is the elastic modulus and strength parameters of surrounding rock, so there is a part of the rock mass parameters inversion. According to the conditions of engineering geology and rock mechanics test results, is not used for inversion of the rock mass mechanics parameters such as Table 1.

Table 1. Is not used for inversion calculated with basic mechanical parameters of rock mass and concrete.

\begin{tabular}{lll}
\hline material & Serious $\left(\mathbf{k N} / \mathbf{m}^{\mathbf{3}}\right)$ & modulus of deformation E(GPa) \\
\hline Anchorage of rock mass around & 25 & - \\
Anchorage concrete & 27 & 30 \\
\hline
\end{tabular}

Model test of anchorage is located in the shallow surface, using gravity stress field of stress field. The surface as the free boundary, model the lateral and underside boundaries are fixed constraint.

Based on the drawing force applied of anchorage in field test, the calculation is processing step by step. The location of grating sensor and the monitoring data are fixed as target of the inversion and contrast.

\subsection{Sample Structure}

According to the test results of elastoplastic parameters and the test data of the same rock, comprehensive analysis is given for inversion parameters and value range. Using uniform design method, the value of interval sample 5 parameters can be divided into four levels (Table 2), then design combination plan of 15 sets of training sample (Table 3).

Table 2. Sample level.

\begin{tabular}{|c|c|c|c|c|c|}
\hline \multirow{2}{*}{ Level figure } & modulus of deformation & poisson's ratio & cohesion & internal friction angle & tensile strength \\
\hline & E/GPa & & $\mathrm{C} / \mathrm{MPa}$ & $\varphi /{ }^{\circ}$ & $\mathbf{R t} / \mathbf{M P a}$ \\
\hline 1 & 0.5 & 0.3 & 0.25 & 31 & 0.03 \\
\hline 2 & 1 & 0.32 & 0.4 & 35 & 0.06 \\
\hline 3 & 3 & 0.34 & 0.55 & 39 & 0.09 \\
\hline 4 & 6 & 0.36 & 0.7 & 42 & 0.12 \\
\hline
\end{tabular}

Table 3. Training Sample.

\begin{tabular}{llllll}
\hline \multirow{2}{*}{ Sample number } & modulus of deformation & poisson's ratio & cohesion & internal friction angle & tensile strength \\
\cline { 2 - 6 } & $\mathbf{E} / \mathbf{G P a}$ & & $\mathbf{C} / \mathbf{M P a}$ & $\mathbf{\mathbf { p } ^ { \circ }}$ & $\mathbf{R \mathbf { H }} / \mathbf{M P a}$ \\
\hline 1 & 0.5 & 0.3 & 0.25 & 31 & 0.03 \\
2 & 0.5 & 0.32 & 0.4 & 35 & 0.06 \\
3 & 0.5 & 0.34 & 0.55 & 39 & 0.09 \\
4 & 0.5 & 0.36 & 0.7 & 42 & 0.12 \\
5 & 1 & 0.3 & 0.4 & 39 & 0.12 \\
6 & 1 & 0.32 & 0.25 & 42 & 0.09 \\
7 & 1 & 0.34 & 0.7 & 31 & 0.06 \\
8 & 1 & 0.36 & 0.55 & 35 & 0.03 \\
9 & 3 & 0.3 & 0.55 & 42 & 0.06 \\
10 & 3 & 0.32 & 0.7 & 39 & 0.03 \\
11 & 3 & 0.34 & 0.25 & 35 & 0.12 \\
\hline
\end{tabular}




\begin{tabular}{llllll}
\hline \multirow{2}{*}{ Sample number } & modulus of deformation & poisson's ratio & cohesion & internal friction angle & tensile strength \\
\cline { 2 - 6 } & $\mathbf{E} / \mathbf{G P a}$ & & $\mathbf{C} / \mathbf{M P a}$ & $\boldsymbol{\phi} /{ }^{\circ}$ & $\mathbf{R t} / \mathbf{M P a}$ \\
\hline 12 & 3 & 0.36 & 0.4 & 31 & 0.09 \\
13 & 6 & 0.3 & 0.7 & 35 & 0.09 \\
14 & 6 & 0.32 & 0.55 & 31 & 0.12 \\
15 & 6 & 0.34 & 0.4 & 42 & 0.03 \\
16 & 6 & 0.36 & 0.25 & 39 & 0.06 \\
\hline
\end{tabular}

\subsection{Elastic-Plastic Rock Mass Parameters Inversion Results}

Established the nonlinear mapping relationship between input and output of 16 samples in Table 3, based on LSSVM and PSO model. On the basis of using particle swarm optimization (PSO) algorithm for global optimization, under the condition of minimum displacement of the objective function of elasto-plastic parameter of the optimal solution, the results such as Table 4. Inversion parameter values are less than the scope of the experiment suggested, in accordance with previous engineering experience.

The optimal parameters are assigned into to the forward calculation model to calculate, load -displacement curve and the calculation results contrast figure, as shown in Figure 2.

Table 4. Anchorage of rock elastic-plastic model parameters inversion results.

\begin{tabular}{|c|c|c|c|c|}
\hline modulus of deformation E/GPa & poisson's ratio & internal friction angle $\varphi /^{\circ}$ & cohesion $\mathrm{C} / \mathrm{MPa}$ & tensile strength /MPa \\
\hline 0.8 & 0.35 & 37 & 0.4 & 0.05 \\
\hline
\end{tabular}

By comparison displacements between measured and calculated can be seen, both on the quantity, the deformation trend is basically the same, showed that the identified basic anchorage of rock elastic-plastic parameters reasonably, showed in Figure 2.

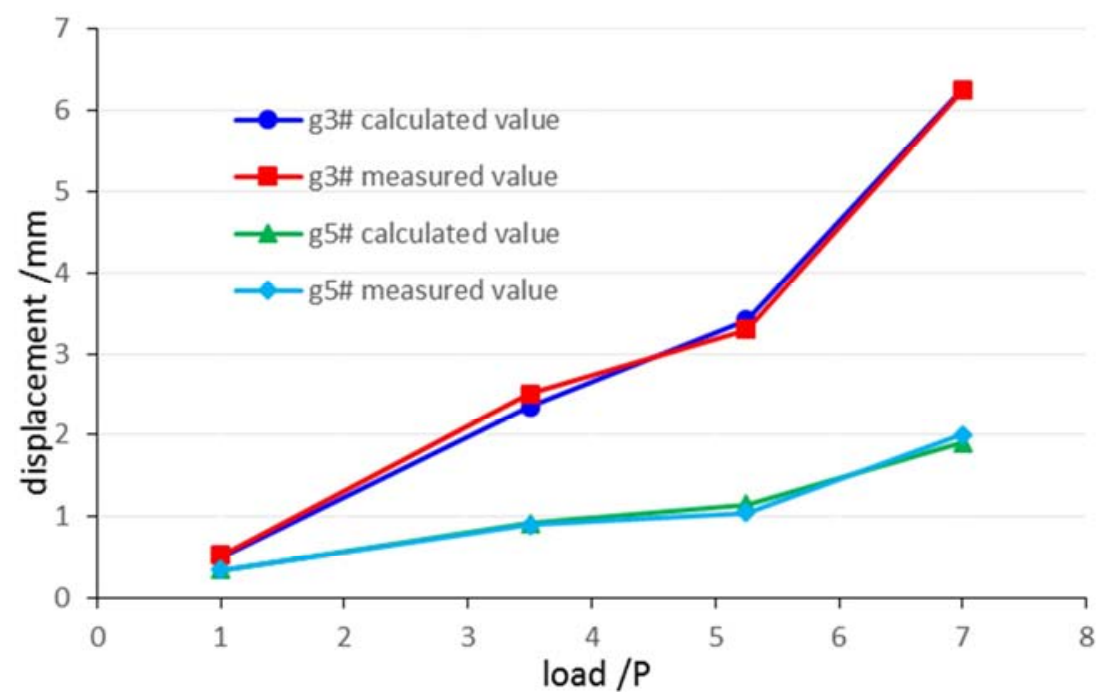

Figure 2. According to the test of displacement load curve model compared with calculated value ( 3 shows before the anchor surface, $\mathrm{g} 5$ shows central pier).

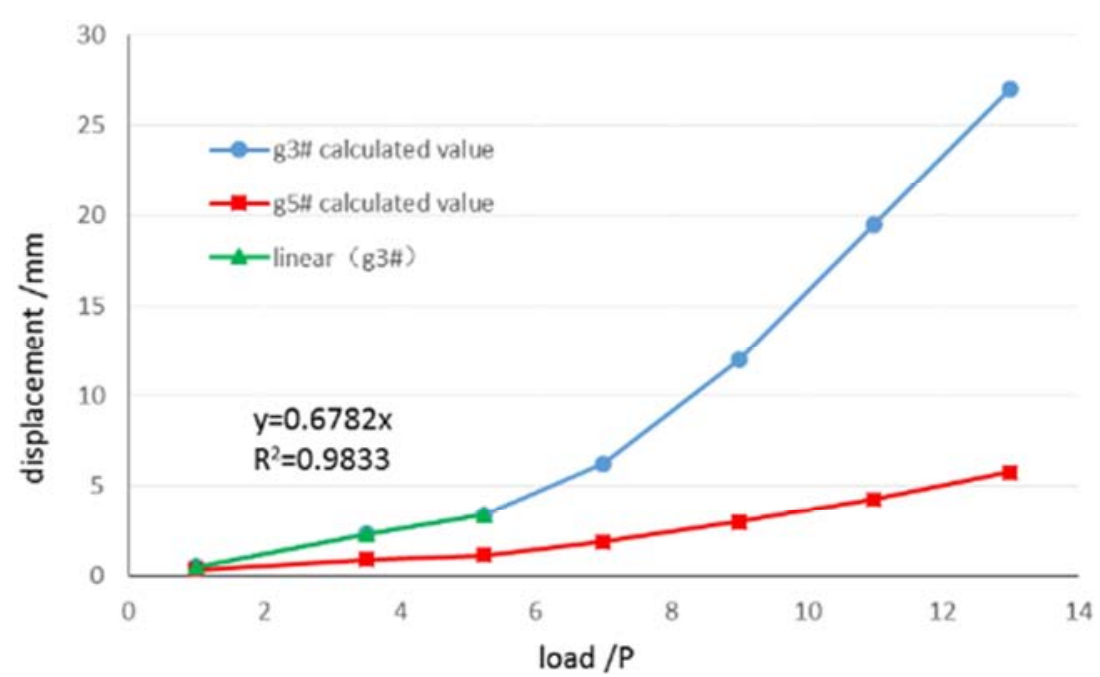

Figure 3. Whole process overload limit displacement curve. 
Overload until destruction, get a load-displacement curve as shown in Figure 3, the whole process and quasi linear and curve. According to Figure 3, main cable load 5.25P is the dividing point of cut-off relationship curves of displacement and load, the pulling force $>5.5 \mathrm{P}$, maximum displacement of anchorage is obviously nonlinear.

Overload to 5.25P, contact parts destructed of the anchor rock before and after, the shear failure zone connected under $7 \mathrm{P}$ overload around and the surrounding rock mainly bearing tension damage during the overload.

\section{Real Bridge Tunnel Anchorage and Rock Mass Structure Three Dimensional Numerical Simulation}

Based on geological generalized model and tunnel anchor rock mass parameters, using FLAC $^{3 \mathrm{D}}$ software to build real bridge tunnel anchorage and rock mass structure model of continuum mechanics, rock mass of the interaction between anchorage and three-dimensional elastoplastic numerical simulation and analysis of the anchorage structure and rock mass deformation mechanism and possible failure modes, the ultimate bearing capacity of anchorage is determined.

\subsection{Tunnel Anchor Design Parameters and the Numerical Model}

The anchoring concrete-plug design for the horseshoe, the longitudinal length of $39.2 \mathrm{~m}$, with the horizontal Angle for $36^{\circ}$, maximum depth of about $180 \mathrm{~m}$, the anchor body center spacing of $27 \mathrm{~m}$. The cross section at the top and bottom adopt circular arc form, the front anchor facet size is $14.82 \mathrm{~m} * 15.7 \mathrm{~m}$, radius is $7.41 \mathrm{~m}$ of the top of the arc, radius is $10.75 \mathrm{~m}$ of the bottom of the arc, the front anchor facet size is $17.7 \mathrm{~m} * 18.97 \mathrm{~m}$ radius is $8.85 \mathrm{~m}$ of the top of the arc, radius is $12.4 \mathrm{~m}$ of the bottom of the arc. Single cable tension is $267035 \mathrm{kN}$. Geological investigation showed that wall rock of anchor tunnel are alteration adamellite granite, granite and grey green dike, more rock mass are broken, in Yaan shore.

Select the center line of the bridge for the $\mathrm{X}$ axis, pointing to the north is positive. Vertical direction to the $Z$ axis is positive upward. $\mathrm{Y}$ and $\mathrm{X}$ and $\mathrm{Z}$ axes right-handed coordinate system. Take the center line of the bridge side tunnel anchor Flac ${ }^{3 \mathrm{D}}$ analysis model is set up. Model contact area use $1.5 \mathrm{~m}$ width entity unit simulation. Calculation in the bridge centerline constraints to the displacement, $\mathrm{Y}$ to simulate two anchor symmetry conditions.

\subsection{The Calculation Steps and Mechanics Parameters}

In the numerical analysis model, firstly, to simulate the excavation of the anchorage of the upper mountain, anchorage tunnel construction excavation and construction, secondly, to design and simulation of main cable load, finally to overload simulate, main cable load imposed by the force surface in front of the concrete anchorage.

Rock mass in the elastic-plastic Mohr - Coulomb constitutive model, anchorage concrete materials by using the linear elastic model. The calculation parameters are shown in Table 5. A 30\% reduction is using to The mudstone parameters of anchor hole vaults and sidewall excavation damage zone reference, not reduction using to plate because considering post-processing.

Due to the tunnel anchorage is located in the shallow, the influence of tectonic stress field is not obvious, so only consider the effect of gravity stress field calculation and analysis.

Table 5. Calculating the basic mechanical parameters of rock mass and concrete.

\begin{tabular}{llllll}
\hline name of rock & serious $\mathbf{k g} / \mathbf{m}^{\mathbf{3}}$ & $\begin{array}{l}\text { modulus of } \\
\text { deformation } \mathbf{E} / \mathbf{G P a}\end{array}$ & $\begin{array}{l}\text { poisson's } \\
\text { ratio }\end{array}$ & $\begin{array}{l}\text { internal friction } \\
\text { angle } \boldsymbol{\varphi} /{ }^{\circ}\end{array}$ & $\begin{array}{l}\text { cohesion } \mathbf{C} / \mathbf{M P a} \\
/ \mathbf{M P a}\end{array}$ \\
\hline $\begin{array}{l}\text { surrounding rock } \\
\begin{array}{l}\text { Anchor rock interface } \\
\text { concrete }\end{array}\end{array}$ & 1 & 0.35 & 37 & 0.4 \\
\hline
\end{tabular}

\subsection{The Excavation Simulation Results}

After anchorage excavation construction, the springback deformation is larger of bottom plate and vault crown settlement is obvious of the rock around the anchorage holes, the largest deformation is up to $72 \mathrm{~mm}$, left and right sides of the cave walls to hole deformation generally $40 \mathrm{~mm}, 65 \mathrm{~mm}$ local (Figure 5).

After anchorage excavation, there is no tension stress zone in arch roof and floor of anchor, appearing tensile stress area around $1 \mathrm{~m}$ range of sidewall. Plastic zone appeared at the top of the anchorage of the arch, backplane, the lateral and medial (central pier side) extended range respectively to $8 \mathrm{~m}, 2 \mathrm{~m}, 4 \mathrm{~m}$ and $6 \mathrm{~m}$, plastic zone of surrounding rock is transfixing of central pier (Figure 6).

\subsection{Design Load Simulation Results}

Anchor tunnel excavation and backfill simulation is completed, the displacement and plastic zone is reset, 1P main cable load imposed by the surface force face in front of the concrete anchorage. Get the deformation Figure 7, plastic zone in Figure 8.

By Figure 7, under design load, wall rock is mainly along sliding displacement of anchorage force direction, the displacement contour approximate anchorage middle wall centered elliptic type (or goose egg) distribution, the maximum displacement is $5.7 \mathrm{~mm}$. Rock mass of anchorage is basicly in compressive stress state, the tensile stress area is small. Anchorage roof and side wall stress relaxation during excavation, the cable's load drawing not before applying 
simulation stress recovery relaxation area, so appearing the plastic zone, but floor rock mass are basicly in flexible stress

state.( Figure 8)

\section{Contour of Displacement Mag. \\ Plane: on \\ Magfac $=0.000 e+000$ \\ $5.3831 \mathrm{e}-004$ to $1.0000 \mathrm{e}-002$ \\ $1.0000 \mathrm{e}-002$ to $2.0000 \mathrm{e}-002$ \\ $2.0000 \mathrm{e}-002$ to $3.0000 \mathrm{e}-002$ \\ $3.0000 \mathrm{e}-002$ to $4.0000 \mathrm{e}-002$ \\ $4.0000 \mathrm{e}-002$ to $5.0000 \mathrm{e}-002$ \\ $5.0000 \mathrm{e}-002$ to $6.0000 \mathrm{e}-002$ \\ $6.0000 \mathrm{e}-002$ to $7.0000 \mathrm{e}-002$ \\ $7.0000 \mathrm{e}-002$ to $7.2613 \mathrm{e}-002$ \\ Interval $=1.0 \mathrm{e}-002$}

tasca Consulting Group, Inc

Minneapolis. MN USA

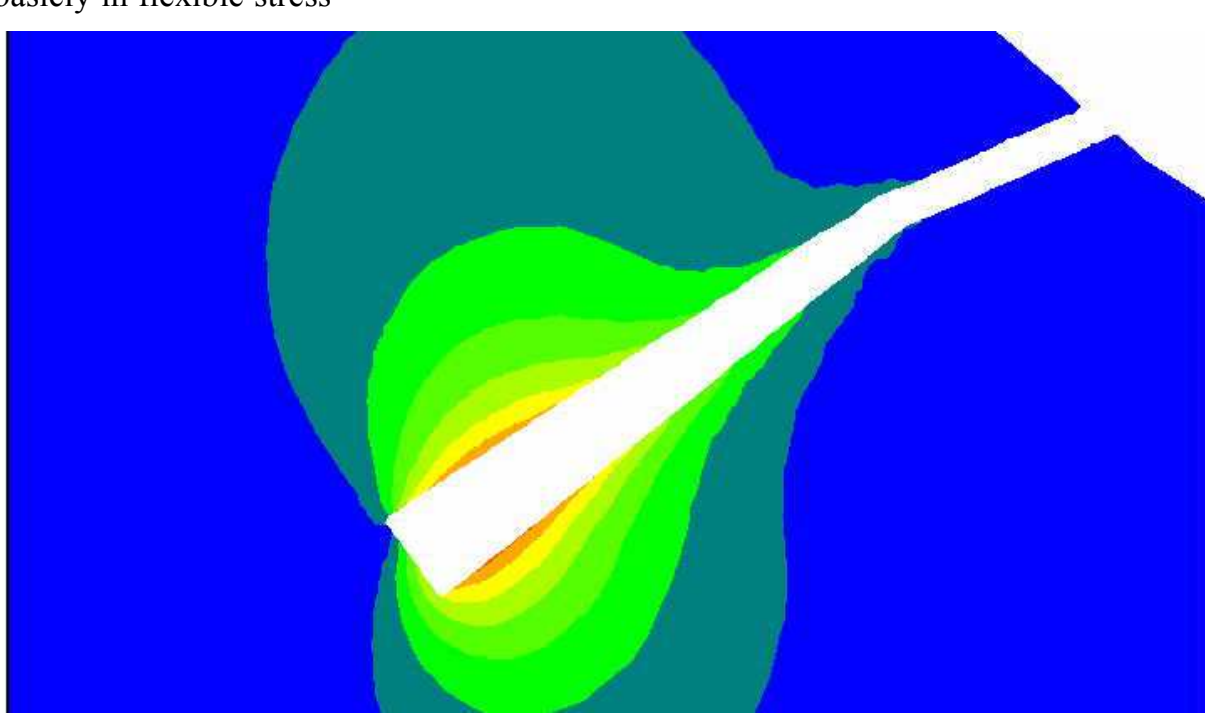

Figure 5. Displacement color area diagram and vector diagram of excavation in anchorage centerline straight section.

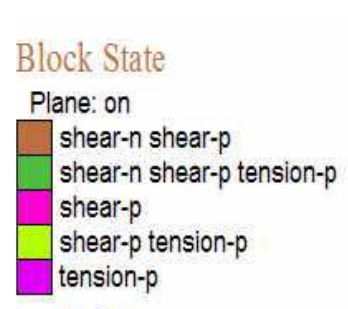

Boundary

Plane: on

Magfac $=0.000 \mathrm{e}+000$

Linestyle

\section{Boundary}

Plane: on

Magfac $=0.000 e+000$

Itasca Consulting Group, Inc. Minneapolis, MN USA

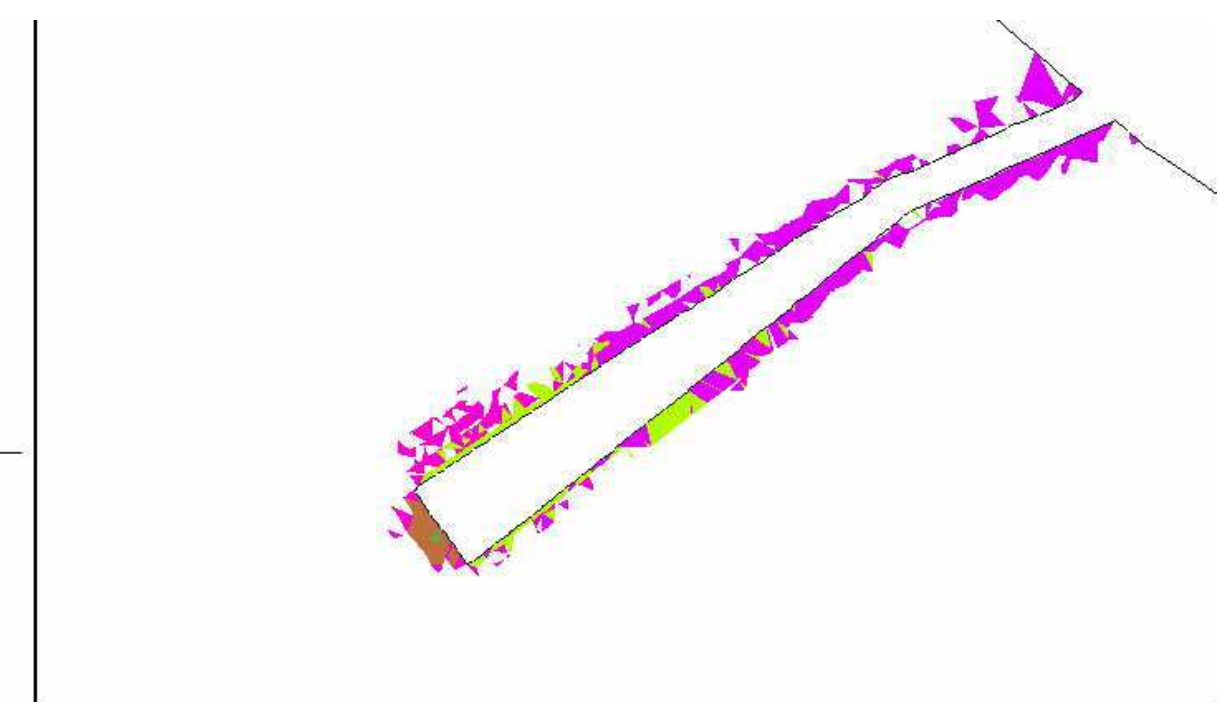

Figure 6. Plastic zone diagram of excavation in anchorage centerline straight section.

Contour of Displacement Mag.

Plane: on

Magfac $=0.000 \mathrm{e}+000$

$5.7017 \mathrm{e}-005$ to $5.0000 \mathrm{e}-004$

$5.0000 \mathrm{e}-004$ to $1.0000 \mathrm{e}-003$

$1.0000 \mathrm{e}-003$ to $1.5000 \mathrm{e}-003$

$1.5000 \mathrm{e}-003$ to $2.0000 \mathrm{e}-003$

$2.0000 \mathrm{e}-003$ to $2.5000 \mathrm{e}-003$

$2.5000 \mathrm{e}-003$ to $3.0000 \mathrm{e}-003$

$3.0000 \mathrm{e}-003$ to $3.5000 \mathrm{e}-003$

$3.5000 \mathrm{e}-003$ to $4.0000 \mathrm{e}-003$

$4.0000 \mathrm{e}-003$ to $4.5000 \mathrm{e}-003$

$4.5000 \mathrm{e}-003$ to $5.0000 \mathrm{e}-003$

$5.0000 \mathrm{e}-003$ to $5.5000 \mathrm{e}-003$

$5.5000 \mathrm{e}-003$ to $5.6902 \mathrm{e}-003$

Interval $=5.0 \mathrm{e}-004$

Itasca Consulting Group, Inc.

Minneapolis. MN USA

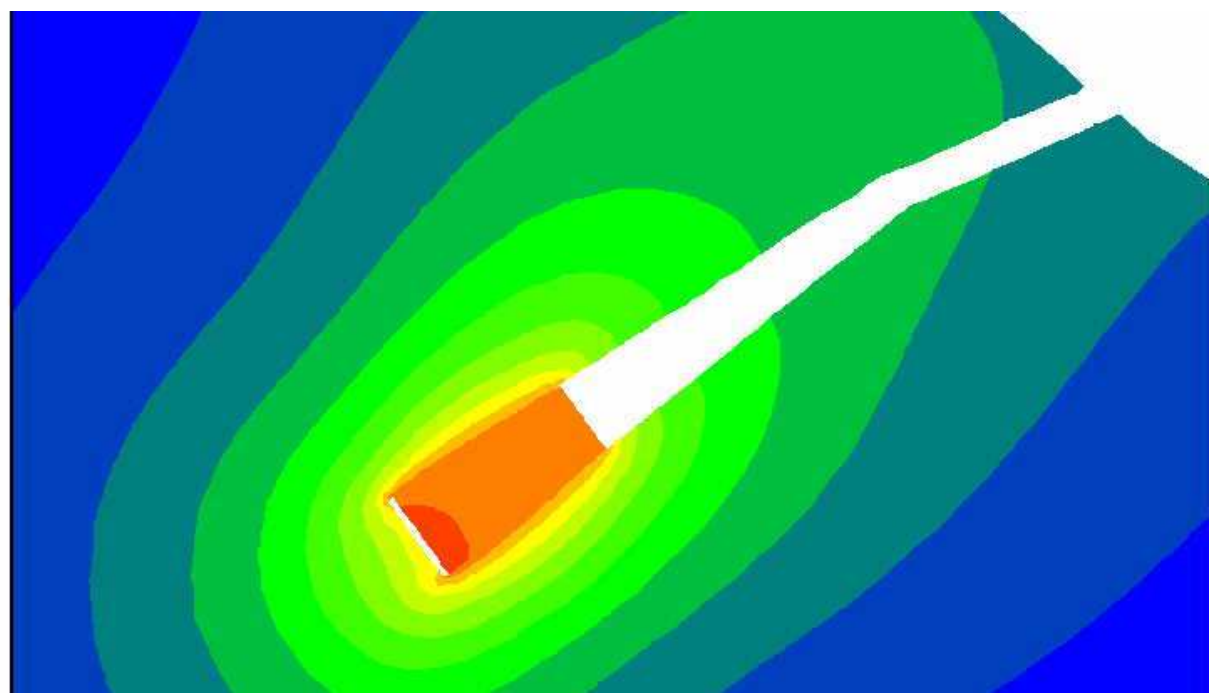

Figure 7. Displacement color area diagram after 1 P loading in anchorage centerline straight section. 


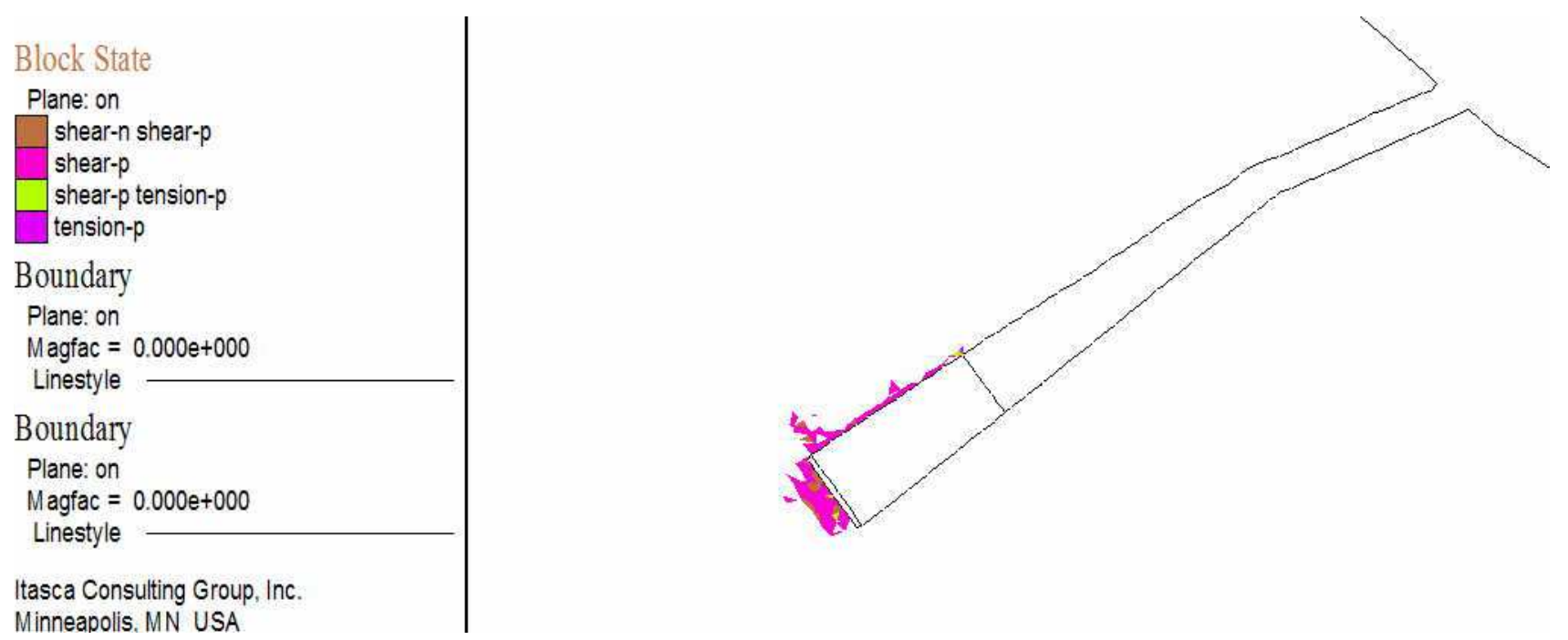

Figure 8. Plastic zone diagram after $1 P$ loading in anchorage centerline straight section.

\subsection{The Simulation Results Overload}

After the 1P loading, step loading is to 13P. Main cable load $7 \mathrm{P}$ is the cut-off point of the relationship between the maximal displacement and load curve, over 7P maximum resultant displacement has quickened significantly. Anchorage tunnel surrounding rock displacement increases with the load increase linearly.

Figure 9 to Figure 10 for 7P, 13P overload of anchorage of surrounding rock displacement diagram, Figure 11 to Figure 12 is the plastic zone distribution map for 7P, 13P when overload. By the displacement of the Figure 9 to Figure 10, displacement isoline distribution under $7 \mathrm{P}$ is similar to $1 \mathrm{P}$, the maximal displacement is $34 \mathrm{~mm}$. After the overload, anchorage along the contact surface faulted, the displacement of anchorage increased significantly than surrounding rock. By Figure 11 to Figure 12, anchor rock rupture is lesser under $7 \mathrm{P}$, anchor rock contact areas appeared shear failure. After ultimate overload, the plastic zone of deep surrounding rock extended, the failure mode of surrounding rock is compressive shear failure. This is because the anchor rock rupture increased significantly, the surrounding rock by wedge anchorage extrusion effect.

\section{Contour of Displacement Mag. \\ Plane: on \\ Magfac $=0.000 e+000$ \\ $1.1961 \mathrm{e}-004$ to $5.0000 \mathrm{e}-003$ \\ $5.0000 \mathrm{e}-003$ to $1.0000 \mathrm{e}-002$ \\ $1.0000 \mathrm{e}-002$ to $1.5000 \mathrm{e}-002$ \\ $1.5000 \mathrm{e}-002$ to $2.0000 \mathrm{e}-002$ \\ $2.0000 \mathrm{e}-002$ to $2.5000 \mathrm{e}-002$ \\ $2.5000 \mathrm{e}-002$ to $3.0000 \mathrm{e}-002$ \\ $3.0000 \mathrm{e}-002$ to $3.4591 \mathrm{e}-002$ \\ Interval $=5.0 \mathrm{e}-003$}

tasca Consulting Group, Inc. Uinneapolis. MN USA

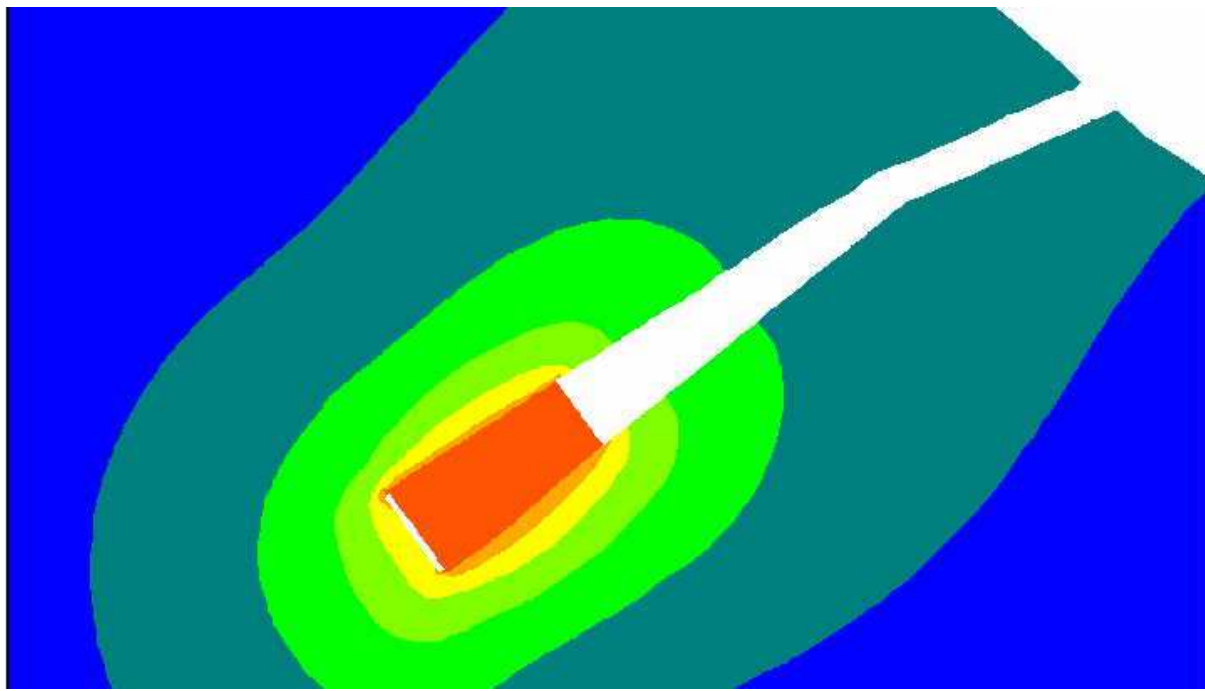

Figure 9. Displacement color area diagram after $7 P$ loading in anchorage centerline straight section. 

Luding in Yaan to Kangding Expressway

\section{Contour of Displacement Mag. Plane: on \\ Magfac $=0.000 e+000$ \\ $2.0878 \mathrm{e}-004$ to $2.0000 \mathrm{e}-002$ \\ $2.0000 \mathrm{e}-002$ to $4.0000 \mathrm{e}-002$ \\ $4.0000 \mathrm{e}-002$ to $6.0000 \mathrm{e}-002$ \\ $6.0000 \mathrm{e}-002$ to $8.0000 \mathrm{e}-002$ \\ $8.0000 \mathrm{e}-002$ to $1.0000 \mathrm{e}-001$ \\ $1.0000 \mathrm{e}-001$ to $1.2000 \mathrm{e}-001$ \\ $1.2000 \mathrm{e}-001$ to $1.4000 \mathrm{e}-001$ \\ $1.4000 \mathrm{e}-001$ to $1.6000 \mathrm{e}-001$ \\ $1.6000 \mathrm{e}-001$ to $1.7046 \mathrm{e}-001$ \\ Interval $=2.0 \mathrm{e}-002$}

Itasca Consulting Group, Inc.

Minneapolis. MN USA

Figure 10. Displacement color area diagram after 13P loading in anchorage centerline straight section.

Block State
Plane: on
shear-p
shear-p tension-p
Boundary
Plane: on
Magfac $=0.000 e+000$
Linestyle
Boundary
Plane: on
Magfac $=0.000 e+000$
Linestyle
Itasca Consulting Group, Inc.
Minneapolis. MN USA

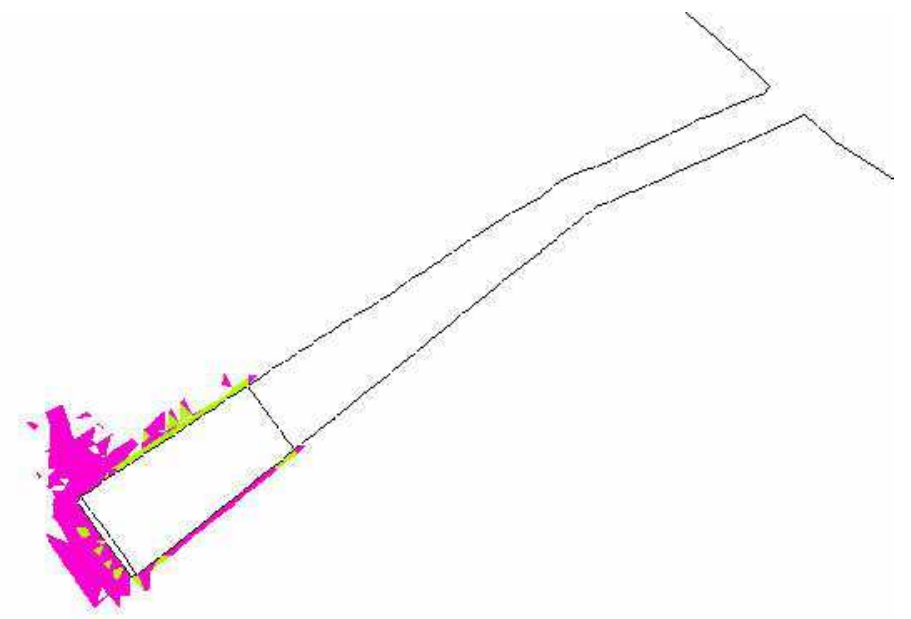

Figure 11. Tensile stress color area diagram after $7 P$ loading in anchorage centerline straight section.

Block State
Plane: on
shear- $n$ shear-p
shear-p
shear-p tension-p
tension-n shear-p tension-p
Boundary
Plane: on
Magfac $=0.000 e+000$
Linestyle
Boundary
Plane: on
Magfac $=0.000 e+000$
Linestyle
Itasca Consulting Group, Inc.
Minneapolis. MN USA

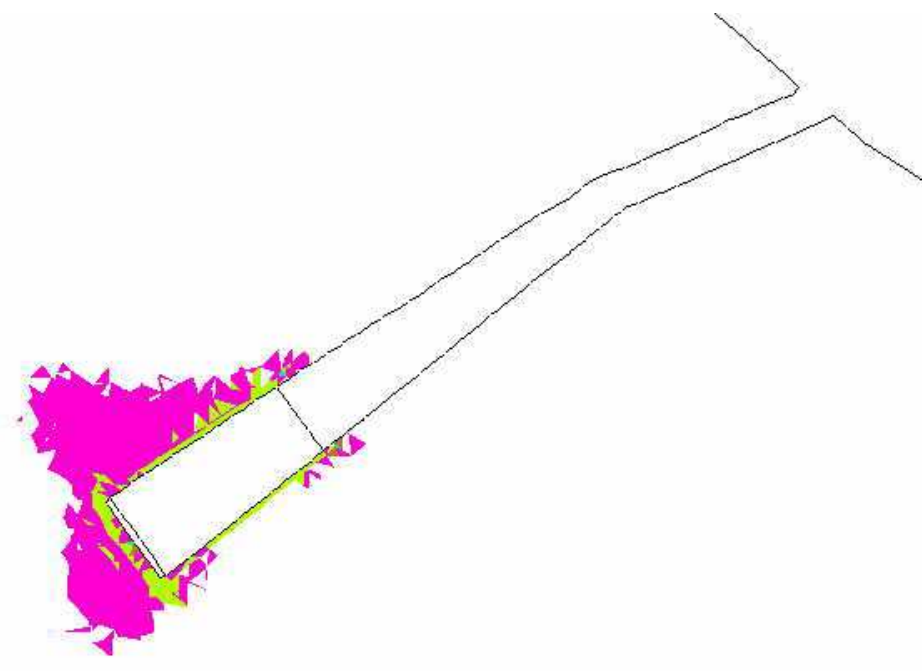

Figure 12. Plastic zone diagram after 13P loading in anchorage centerline straight section. 


\section{Conclusion}

The inversion granite parameters is $E=0.8 \mathrm{GPa}, \varphi=37^{\circ}, c$ $=0.4 \mathrm{MPa}, R t=0.05 \mathrm{MPa}$ based on 1: 10 model test, the value within the scope of the experiment suggested, in accordance with previous engineering experience.

After anchorage excavation construction, the springback deformation is larger of bottom plate and vault crown settlement is obvious of the rock around the anchorage holes, the largest deformation is up to $72 \mathrm{~mm}$, left and right sides of the cave walls to hole deformation generally $40 \mathrm{~mm}, 65 \mathrm{~mm}$ local. There is no tension stress zone in arch roof and floor of anchor, appearing tensile stress area around $1 \mathrm{~m}$ range of sidewall. Plastic zone appeared at the top of the anchorage of the arch, backplane, the lateral and medial (central pier side) extended range respectively to $8 \mathrm{~m}, 2 \mathrm{~m}, 4 \mathrm{~m}$ and $6 \mathrm{~m}$, plastic zone of surrounding rock is transfixing of central pier.

Under the design load, the tunnel anchor maximum displacement is $5.7 \mathrm{~mm}$, anchorage roof and side wall stress relaxation zone is in the plastic zone, floor rock mass basicly in a flexible state.

Increase the load to $7 \mathrm{P}$, shear failure and anchor rock contact area, the displacement of anchorage is nonlinear. Under the overload condition, the anchor rock rupture increased significantly and produce compression, the plastic zone developed to top of deep surrounding rock, failure mode is changed to compressive shear failure.

\section{References}

[1] The Professional Standards Compilation Group of the Peoples Republic of China. Design specification for highway suspension bridge ((JTG/T D65-05-2015)) [S]. Beijing: China Communications Press, 2015. (in Chinese)

[2] ZHU Yu, WEI Jun, LI Hao, ect al. Analysis of Displacements of Tunnel-type Anchorage for a Large-span Suspension Bridge.
[J] Chinese Journal of Rock Mechanics and Engineering, 2005, 24(19): 3588-3593. (in Chinese)

[3] ZHU Yu, LIAO Chao-hua, PENG Yuan-cheng. Design and Structural Capacity Assessment of Tunnel-Type Anchorage for Long-Span Suspension Bridge. [J] Bridge Construction, 2005, 2(2): 44-46, 73. (in Chinese)

[4] ZHU Yu, WEI Jun, LI Hao, ect al. Support capability of tunnel-type anchorage of a long-span suspension bridge. [J] J. Huazhong University of sci. \& Tech. (Nature Science Edition, 2005, 33(7): 90-93. (in Chinese)

[5] WU Aiqing, PENG Yuancheng, HUANG Zhengjia, et al. Rock mechanics comprehensive study of bearing capacity characteristics of tunnel anchorage for super-large span suspension bridge [J]. Chinese Journal of Rock Mechanics and Engineering, 2010, 29(3): 433-441. (in Chinese)

[6] XIAO Benzhi, WU Xiangchao, PENG Chaoquan. Stability of The Anchorage Wall Rock of Tunnel for Chongqing Egongyan Bridge. [J] Chinese Journal of Rock Mechanics and Engineering, 2005, 24(Supp. 2): 5591-5597 (in Chinese)

[7] WU Xiangchao, XIAO Benzhi, PENG Chaoquan. A study on rock mechanical parameters of east anchorage of Egongyan Bridge across Yangtze River in Chongqing [J]. Underground Space, 2003, 23(2): 132-138. (in Chinese)

[8] HU Bo, ZHAO Hai-bin, WANG Si-jing, et al. Pull-out model test for tunnel anchorage and numerical analysis [J]. Rock and Soil Mechanics, 2009, 30(6): 1575-1582. (in Chinese)

[9] Dong Zhihong, Zhang Qihua, Ding Xiuli, etc al. Numerical Analysis of Rockmass Stability in Tunnel Anchoring of Aizhai Bridge. [J] Journal of Yangtze River Scientific Research Institute, 2005, 22(6): 54-58. (in Chinese)

[10] Wu Kai, SHENG Qian, etc. A model of PSO-LSSVM and its application to displacement back analysis [J]. Chinese Journal of Rock and Soil Mechanics, 2009, 30(4):1109-1114. (in Chinese) 